\title{
UNA PERSPECTIVA SEMIÓTICA DE LA CIUDAD DE BOGOTÁ
}

\section{EDER GARCÍA DUSSÁN ${ }^{* *}$}

\section{Resumen}

No hay grieta entre el ciudadano y los espacios físico y simbólico de la metrópoli que lo habita, pues la articulación de su hacerse histórico está ligado al ordenamiento social que lo detemina. Pensar, entonces, la ciudad como espacio que constituye el orbe social en dialéctica con el pensamiento y el accionar humanos, permite lanzar líneas de sentido que pemiten interpretar la ciudad de Bogotá a partir de cuatro categorías de comprensión: ciudad como conjunto de signos, como jaula, como promesa y como escenario productor de imaginarios sociales. Así las cosas, la mirada hacia la ciudad, resulta siendo una mirada hacia nosotros mismos como formas culturales de producción a la vez que como productos de sus efectos.

\section{Palabras clave}

Cultura urbana, terror, es cenario gótico, comunidad imaginada, memoria colectiva, lógica mestiza, disciplinamiento corporal, zapping, imaginario social, neobarroco.

\section{ABSTRACT}

There is no gap between the citizen and the physical and symbolic sites of the metropolis that inhabits him, because his becoming a historic being is linked to the social order that determines him. Then, thinking about the city as a space that constitutes the social orb, in a dialectical relation with human thoughts and actions, allows us to draw lines of sense that can be used to interpret the city of Bogotá, by means of four comprehension categories: the city as a set of signs, as a cage, as a promise and as a social imaginery production scenario. In consequence, the look at the city becomes the look towards ourselves, as cultural production agents and also, at the same time, as products of its effects.

Para enunciar sobre algo se debe estar en algún lugar -de poder- desde dónde hacerlo, desde un espacio ordenado socialmente, es decir, desde una cultura. En nuestro caso, queremos enunciar y denunciar a propósito de la Cultura Urbana, es decir, aquella construcción simbólica que es producto de la interacción entre unbanitas, para usar el término de Simmel.

Sabemos que con el desplazamiento de lo rural a lo urbano se gana una interacción personal más funcional y compleja, formándose un proceso que culmina en la pérdida del compadrazgo y de la vida aldeana. La socialización de la existencia urbana permite paulatinamente el crecimiento de una soledad en la

\footnotetext{
"*ilósofo. Magíster en Lingüística Española. Profesor de la Universidad Pedagógica Nacional.

${ }^{1}$ Cfr. Simmel, G. "El individuo y la libertad. Ensayos de crítica de la cultura" Barcelona: Península, 1986 pág 240 y ss.
} 
colectividad, con lo cual se instaura una reestructuración al interior de la institución familiar y sus espacios de convivencia. A partir de estos cambios, ¿cómo pensar la actual ciudad?, ¿cuál es su mapa y la mecánica de sus escenarios?, ¿cuáles son los lugares y las instituciones que organizan su dinámica?; en suma, ¿cómo dar razón de la imagen de nuestro proceso cultural a través de una cierta mirada sobre Bogotá?

En adelante abordaremos la cuestión de la ciudad como punto de re-flexión semiocomunicativa, apoyados esencialmente en los parámetros esenciales del crítico uruguayo Ángel Rama ${ }^{2}$. Desde esta perspectiva, la ciudad es doble: configuración física y espacio simbólico de operación. Como arte-facto de producción sociocultural, la ciudad es física y simbólica (meta-física). Una maraña de calles que presentan infinidad de signos, es decir, un megadiscurso cuyas diversas 'sentidificaciones' dan cuenta de los cuerpos de concreto y de los cuerpos de carne y hueso que reflejan las estructuras de poder que mantienen la ciudad que habitan, a la vez que expresan su modelo cultural y su ordenamiento social.

La ciudad, al mezclar cuerpos inertes y orgánicos, se muestra como colcha de retazos, como costura, y es en esa con-fusión de intemediaciones donde aflora la urbanidad de la ciudad. Ciudad-mosaico, pues es un lugar de mezclas; mixtura de colores, ruidos, formas, signos, ideologías y relatos (imaginarios) que se transmiten de generación en generación y que realizan las ciudades en su hacerse crono-lógico y en su naturaleza histórica que no hace más que reflejar sus efectos para que, al momento, sean revisados por el ojo humano. Tal como afima Calvino: "(...) El ojo no ve cosas sino figuras de cosas que significan otras cosas... La mirada recorre las calles como páginas escritas: la ciudad dice todo lo que debes pensar, te hace repetir su discurso y (mientras la recorres) no haces sino registrarlos nombres con los cuales se define a símisma y a todas sus partes". Si esto es así, entonces, no se mira en la ciudad, sino que ella re-conoce y condiciona las miradas de aquellos que la (pre)ocupan, tal como sucede en la experiencia de observar aparadores y estanterías. Las vitrinas son ventanas urbanas donde queda reducida algo de cada ciudad y su ethos, es decir, de sus múltiples formas de vida. "Una vitrina señala la forma como los usuarios perciben el mundo, sus distancias, sus anhelos. Cada vitrina resuelve teatralmente la relación de las cosas con las personas... las cosas que circulan por las vitrinas corresponden a las cosas que usan las personas; por ello los límites de las vitrinas, sus verdaderas fronteras, no serán otros que la misma ciudad; y dentro de esos límites la ciudad misma es vista por sus vitrinas. Las vitrinas identifican la ciudad. La ciudad toda es una gran vitrina"3.

${ }^{2}$ Cfr. Rama, A. "Ciudad letrada" Hanover: Ediciones del Norte, 1984.

${ }^{3}$ Silva, A. "Imaginarios urbanos" Bogotá: Tercer Mundo, editores. Tercera edición, 1997. 
Ahora bien, con el ánimo de vislumbrar mejor esta forma de reflexionar la ciudad, y en especial Bogotá D. C. como un gran libro, nos apresuraremos a analizarla a través de cuatro categorías de comprensión, que nos servirán como punto de apoyo para adelantar una lectura de sus espacios físicos y simbólicos. Éstas son, ciudad como conjunto de signos, como jaula, como promesa y como escenario productor de imaginarios sociales.

\section{Ciudad como conjunto de sistemas sígnicos}

Toda metrópoli es un escenario que regula la actividad social, condiciona los comportamientos más íntimos del sujeto y constituye un plus de sentidos a través de elementos sígnicos como carteles, dibujos, leyes sociales, dinamismo de discursos, etc. y de espacios arquitectónicos donde éstos se habilitan y se conservan, tomando materialidad bajo el dinamismo de complicados sistemas sígnicos apresados en anaqueles, habitaciones, muros, autopistas, fábricas, esquinas y cuerpos humanos que quedan cultivados bajo sus órbitas. Ya desde la Polis griega, todo su sostén simbólico (nomos, experiencias est-éticas, filosofía, etc.) se mantenía gracias a la creación de un espacio físico, el ágora, vale decir, la plaza pública, a la cual se le as ocian prácticas de poder que permite la aparición del ciudadano. Sabemos, pues, que desde una perspectiva filosófica, la ciudad es un aparato de comunicación ${ }^{4}$, es decir, un espacio que permite la posibilidad de hacer valer una opinión a través del uso público de la razón (Kant), en todas las decisiones de la vida comunitaria para, a través de un pasado común, consolidar un futuro. Es así como comprendemos a Calvino cuando afirma: "(...) la ciudad está hecha de relaciones entre las medidas de sus espacios y los acontecimientos de su pasado... Pero la ciudad no dice su pasado, lo contiene como las líneas de una mano, escrito en las esquinas de las calles, en las rejas de las ventanas, en los pasamanos de las escaleras, en las antenas de los pararrayos, en las astas de las banderas...."

La idea de una mirada que repercute dialécticamente en la metrópoli (alguien mira para terminar siendo mirado, atrapado y provocado) ${ }^{6}$ se liga, pues, a un espacio ávido de signos que subsisten sólo en tal dinamismo que permite ver lo que ha de ser visto en una 'complejidad organizada' y controlada. Es así como comprendemos que la arquitectura metropolitana almacena la capacidad sígnica de una ciudad al tiempo que la hace funcionar como la síntesis de formas de

\footnotetext{
${ }^{4}$ Cfr. Hare, R. "Wofur sind Stadte da? Die Ethic der Standtplanung" En: Meggle, G. Zum moralistchen Denken, Bd, 2, Frankfurt, 1995 pág. 187 yss.

${ }^{5}$ Calvino, I. "Las ciudades invisibles", Madrid: Biblioteca El Mundo. 1999, pág. 25

${ }^{6}$ Piense el lector en aquellas experiencias est-éticas propias de los últimos años provocadas en la carrera séptima de Bogotá, que se convierte por un tiempo en ciudad-museo consistente en la exposición de pictografías que atrapan, en órdenes estéticos muy visibles, la cotidianidad del bogotano en ciclovía, caminando presuroso por la calle, transportándose en los buses de Transmilenio, recorriendo parques, etc. Aquí, el transeúnte se acerca inocente a mirar y tras una exposición de su mirada se mira en su vida cotidiana y privada. Alguien/algo lo mira, y ya no tiene más que aceptar que está expuesto, inscrito, aceptando así que su intimidad es pública o que su vida pública es la vivida por todos como única.
} 
interacción y finalidades humanas; es por esta razón que la ciudad es una configuración de expresiones y sentidos que se inscriben a cada momento en su cuerpo, a la manera de un tablero que conserva palimpsestos $y$, tras su inscripción, quedan como elementos listos a ser observados, a través de una mirada caleidoscópica llamada zapping; expresión tomada de Omar Calabrese para referir el fenómeno consistente en cambiar de canal mediante control remoto, e incluso sin él, hasta que el usuario se detiene en uno que atrapa su curiosidad y al desaparecer ésta vuelve de nuevo a saltar de canal y así sucesivamente. El efecto es la percepción desordenada de incontabilís imas imágenes percibidas en poco tiempo a las que, incluso, algunos jóvenes pueden darle un sentido, lo cual se aproxima mucho a la visión del esquizofrénico.

\section{Ciudad Como Jaula}

Por otra parte, des de el punto de vista físico la ciudad está hecha por el espacio público; esto define lo urbano como la suma de lugares que permiten la convivencia y la socialización de sus integrantes. Sin embargo, muchos espacios hacen que la ciudad sea más bien una máquina que enjaula y tortura los cuerpos, que los moldea tiránica y subliminalmente, desintegrando la ciudadanía misma.

La ciudad, vista desde una perspectiva semiótica puede ser considerada como aquella matriz donde la gente se vuelve objeto y su poder de imaginar pasa a las cosas que se vuelven no solo como la gente sino como sus perseguidores. Se convierte así en el campo donde el terror avala prácticas que se deslizan en una ética tecnológica. El terror ya no es la práctica de los campos de concentración alemán, sino una es pecie de sortilegio que recae sobre los cuerpos hasta hacerlos domésticos y eclipsados. La alta sobreexposición y la masificación conducen a la necesidad de superar el encierro, la prisión y la violencia física. Son ahora los materiales de la comunicación (teléfonos intervenidos, radio, satélites, etc.) los que actúan como los nuevos centinelas que rondan y producen un terror regular, por lo que no resulta gratuito recordar la tesis de Foucault de la sociedad disciplinada por un juego de miradas; en una palabra: Sociedad Panóptica que en las grandes urbes, no hace más que dinamizarse bajo la dicotomía vigilancia/castigo. Nos convierte así el espacio urbano en sujetos metropolitanos remolcando un síntoma que ya no es tanto la violencia sino el terror, un arma tan poderosa que tiene la función de hacer circular saturadamente una mirada anónima, negando todo poder de reciprocidad, hasta el punto que hace repeler/evadir al sujeto, quien convive con la sensación de ser rondado a todo momento, incluso en ausencia del vigía. Así, por ejemplo, el conocimiento de que en el centro de Bogotá existen ubicadas en los altos edificios cámaras del DAS o de la Policía Metropolitana, vigilando las actividades del ciudadano romo, o de las cámaras de seguridad en los edificios bancarios, en los almacenes de cadena, etc. Siempre no miran, nos vigilan, nos controlan, y no sabemos exactamente quién ni desde dónde. 
Hablamos así de terror puesto en marcha sobre un escenario altamente gótico ${ }^{7}$ : ciudad opaca, laberíntica ${ }^{8}$, inhumana, caótica y angustiante ${ }^{9}$; una ciudad concertada como cuerpo inorgánico desarticulado y sin coincidencias y cuyo ordenamiento peculiar produce efectos sintomáticos en nuestros cuerpos biopsico-sociales, dentro de los cuales subrayamos lo om inoso, experiencia que tiene que ver justamente con ese hecho de que, al tiempo, una experiencia social resulta muy familiar y al tiem po muy lejana; contradicción que produce el afecto de la angus tia, de la petrificación pasajera y que no es algo nuevo o ajeno, sino algo familiar de antiguo a la vida anímica, simplemente transferido de ella por el proceso de la re-presión, es decir, de la actividad inconsciente ${ }^{10}$.

Esta sensación ominosa producida por la ciudad-laberinto, es reforzada por la malla vial y las zonas paralelas como las ciclo ruta y caminos peatonales, apoyados en ecosistemas artificiales que muchas veces no hacen más que enmascarar, sin lograrlo del todo, espacios sis temáticamente deformes como la de algunos barrios del sur de Bogotá o el barrio Entreríos, que contiene en su centro un caño bastante esperpéntico apenas limitado por una desolada ciclo ruta. También las calles de San Victorino, las zonas desoladas de Bogotá (que es toda ella después de las once y media de la noche). La angustia también es promovida pon la presencia de los policías (tantas veces amigos de los delincuentes), por la

\footnotetext{
${ }^{7}$ Estilo artístico caracterizado por bóvedas y esbel tos pilares que producen la sensación de misterio, como las catedrales de las ciudades de Bogotá y Lima, entre otras.
}

${ }^{8}$ Piense el lector(a), por ejemplo, en la topografía laberíntica de Bogotá: calles, carreras, diagonales, transversales, recovecos, medias cuadras, enredos viales etc. A pesar de ello, una contradicción se hace evidente; el casco urbano bogotano, sin geométricamente exacto, conserva nomendadores que sí son matemáticamente exactos. No usamos nombres que conservan referencias históricas concretas aunque existen avenida Quito ( $\mathrm{K} 30)$, Avenida Santander $(\mathrm{Cl} 68)$, Cali ( $\mathrm{K} \mathrm{86}$ ), Medellín ( $\mathrm{Cl} 80$ ) etc, sino usamos nomendadores matemáticos. Tal como expone A. Rama en su Ciudad Letrada: "(en) Bogotá se ha impuesto un nomenclador más numérico preciso y rígido que el de Manhattan: las ubicaciones pueden hacerse exclusivamente con números fijando exclusivamente el lugar de la cuadra en la que se encuentra la casa: 25 N $^{\circ} 3-70 . . . "$ (p. 36). Pero, agregamos, una matemática falible: la carrera 30 deviene la autopista norte que no se sabe si es la calle 14, la 15 o la misma carrera 30 ; la calle 13 es a la vez la 15 después de la 72 ; la calle 68 es la calle 72, y también es avenida etc. Efecto éste que evidencia la "madriguera" citadina bogotana a nivel de su mapa espacial. En la actualidad resulta interesante cómo las estaciones de Transmilenio mezdan éstas dos formas de ubicación, al nominarlas con contraseñas y nomencladores matemáticos.

\begin{abstract}
${ }^{9}$ Por la época de afianzamiento de este escrito, el œntro de Bogotá presenta un espacio que interesa comentar a vuelapluma: un recorrido por la carrera décima entre las calles 11 y 6 , dejan ver primero un Centro Comercial que revela desde muy temprano una actividad comercial opulenta. En la siguiente cuadra, una cuadra destrozada, como si hubiera sufrido un ataque aéreo y, cuestión audaz, al lado de ese tenebroso panorama, una actividad comercial paupérrima adelantada por un amplio grupo de desplazados que venden sus pertenencias para sobrevivir. La siguiente cuadra deja ver el parque Tercer Milenio, muy ordenado, florido, bien vigilado. Finalmente, una cuadra con construcciones antiquísimas, coloniales, verdaderas madrigueras de donde salen y entran prostitutas, travestís, ladrones, gamines (golfillos), -y también policías-
\end{abstract}

${ }^{10}$ Cfr. Freud, S "Lo ominoso" (1919) En: O. C. Buenos aires: Amorrortu, 1991, Tomo XVII p. 240241. 
desconfianza para asistir al estadio saturado de jóvenes violentos, pero también suscitada por el miedo a hablarle al Otro, por el miedo al habitante de la calle, al gruñón conductor, o a los laberintos artificiosos que forman los automóviles públicos en la carrera décima de Bogotá, que no se sabe si produce más angustia atestada de buses y peatones o casi desértica un domingo por la tarde o un día festivo.

Se comprende así la ciudad como una caja que instituye la cotidianidad de los sujetos y ordena los espacios de su interacción. El sujeto, entonces, cae y descansa sobre un lugar ayudando a producir sus sentidos históricos cuyo correlato en su cuerpo es la inscripción de efectos psicológicos y simbólicos. Tal como afirma Pardo, "No es que solamente nosotros ocupemos un espacio, los espacios, desde el principio y de antemano nos ocupan; es decir, nos preocupan"11, con lo cual invertimos el sentido común, esto es, la forma como habitualmente creemos compro-meternos con la ciudad. Efectivamente, el espacio urbano nos pre-ocupa y deter-mina toda nuestra escala conductual; concurrencia registrada también en la acción de encubrir los mensajes a través de la tras posición o la sustitución sobre cuerpos no humanos, como el uso repetitivo de mensajes publicitarios en vallas y en los mass media, hasta terminar en la acción de tatuar, de paso, los cuerpos orgánicos, como el caso de los jóvenes barristas capitalinos que inscriben en sus brazos los escudos del Club Los Millonarios o Independiente Santa Fe, como muestra de que sus cuerpos se someten a una lógica de exclusión basada en la dicotomía de dos colores (con larga historia de violencia en Colombia, por demás ): azul y rojo.

Volviendo a ejemplificar con nuestra ciudad, evidentemente nadie quisiera vivir en la Bogotá de 1850 que no pasaba de 30.000 habitantes (mientras por esa misma época Buenos Aires, por ejem plo, pasaba de 300.000) y donde las cifras arrojaban un analfabetismo del $80 \%$, en un país de apenas 747 universitarios estudiando en una aldea am enazada por la epidemia del cólera. Pero, tampoco se quiere vivir en urbe actual, ciudad de masas con más de 8'000.000 de habitantes y que recibe a diario docenas de desplazados, con una tendencia cada vez mayor hacia la privatización y re-tribalización de la vida social, y cuyo resultado de la mezcla de ambos procesos es una sociedad fragmentada, es decir, una fraternidad debilitada lo cual genera una paradoja adicional: las personas viven y trabajan intensamente bajo presión física y psicológica, pero sus relaciones con los otros se mantienen curiosamente superficiales. Así, Bogotá no es una ciudad donde el compromiso real respecto a los demás tenga mucho sentido.

No se puede negar que actualmente se vive en una Bogotá encauzada cada vez más hacia una privatización del espacio público, reflejada fundamentalmente en la proliferación de los conjuntos cerrados, habitados por estratos sociales homogeneizados y separados del resto de la ciudad por una fuerza de seguridad privada o por sus propios medios de seguridad. Lo mismo que ocurre en los barriadas populares, pero con mecanismos como las pandillas o los grupos de

\footnotetext{
${ }^{11}$ Pardo, J. L. "Las formas de la exterioridad”, Valencia: Pre-textos, 1992, pág.16. 
autodefensa barrial; todos ellos guiados por una antipatía radical. Tal retribalización la interpretamos como un síntoma del rencor hacia lo externo inmediato que afecta enomemente la vida pública de Bogotá ${ }^{12}$, ese rencor que según el filósofo Max Scheler consideraba como la fuente de todo mal. Este resentimiento, acentuado cada vez más en nuestro medio y materializado por la guerra regionalista (de la cual la segunda versión del Reality Show Expedición Robinson, "El desafío" subrayó como versión est-ética moderna) produce una identificación construida por la exacerbación de las diferencias con los otros y que son finalmente, comunidades imaginadas, porque los miembros de esas microcongregaciones desconocen la mayor parte de aquellos que se identifican como miembros de tal grupo y no obstante, comparten la imago (imaginario colectivo) de su común-unión ${ }^{13}$. Este encerramiento o re-tribalización acentúa las identidades comunales, evidenciada a través de varios comportamientos actuales de nuestras ciudades, de la cual Bogotá es buen ejemplo. As í, el rechazo a la regulación del tráfico por los semáforos, lo que es un síntoma visible de la no-aceptación del espacio y las reglas públicas; el semáforo y las regulaciones de tráfico se perciben como un obstáculo para la libertad de movimiento de los carros particulares y la calle se convierte no en un lugar de encuentro, sino en una vía instrumental para la movilización ${ }^{14}$.

Divergencia también evidente en el uso del es pacio público que a su vez se refleja en la no coincidencia de los tiempos, que nos hace fluctuar en lo que Ramón de Zubiría llamó apropiadamente "la cultura del más o menos"15 Discordia, pues, contenidas en el hábitat metropolitano que no cesa de inscribir en sus espacios urbanos contradicciones y que la literatura plasma con agudeza. Así el caso, entre muchos, de la obra de Chaparro, "Opio en las Nubes". En uno de sus apartados se puede leer con un novedoso estilo: “(...) La calle. La noche. Unas babas. Dos babitas. Tres babitas. La suciedad. Las luces de neón. Un dis paro en la os curidad. Un cuerpo. Dos cuerpos. Un cigarrillo. La ropa. Los autos. Los perros. Las putas y los bares. Los árboles y las canecas trip trip trip. Las ventanas. Los ros tros que se asoman por la ventana. Las puertas. Los perros. Guau, guau. Otro disparo. Pum. Mierda. Ugh .zas. un vidrio roto. Una sirena. Una puta que corre. La ropa. Un árbol. El aire. La calle..."16.

\footnotetext{
${ }^{12}$ Al respecto, consulte el lector (a) el excelente comentario del Profesor Rubén Jaramillo. Cfr. Jaramillo Vélez, R. "El rencor ante la ciudad" En: Torres Tovar, C (Et Al) La ciudad: Hábitat de diversidad y complejidad Universidad Nacional de Colombia, 2000 pág. 72-82.

${ }^{13}$ Cfr. Anderson, B. "Comunidades imaginadas. Reflexiones sobre el origen y la difusión del nacionalismo", México: Fondo de Cultura Económica, 1991.

${ }^{14}$ Cfr. Sennett, R. “El dedive del hombre públiœ” Barclona: Península, 1978 pág. 25.

${ }^{15}$ Cfr. Segura, C \& Cabarcas, H. "La dignidad del coraje. Textos de Ramón de Zubiría". Colección el "Álamo y el Ciprés 2" Bogotá: Instituto Caro y Cuervo y Universidad de los Andes, 1998 pág. 279-283.

${ }^{16}$ Chaparro Madiedo, R . "Opio en las nubes" Bogotá: Proyecto Editorial, 1998 p. 35. Al respecto, consulte también el lector(a) también la compilación de auentos agenciada por la profesora Luz 
Pero, a pesar del constante condicionamiento que impone el espacio urbano sobre el cuerpo, el cuerpo es impertinente; impertinente por estructura; por estructura de lo social, y por esto se manifiesta marcándose con signos (síntomas como la bulimia, la anorexia, la neuritis, la neuralgia, los efectos del estrés, etc.), y más si pensamos en el cuerpo de la mujer que ha tenido que llevar el peso de una jerarquía particularmente fálica en Occidente basada nuevamente sobre una lógica de la exclusión ${ }^{17}$.

Pero, justamente en este movimiento de avances, retornos y amasijos de síntomas en los cuerpos de los ciudadanos, se van fijando los saberes, las narraciones y la memoria colectiva, esta que según los psicólogos es uno de los mecanismos que organizan espacialmente el conocimiento a través de sistemas geométricos, calles, edificios, etc. Nuevamente Calvino: "La memoria es redundante: repite los signos para que la ciudad empiece a existir"18. La ciudad, entonces existe en la memoria colectiva, en la imagen mental de quien termina siendo habitado por ella. La memoria urbana formada con la materia de sus espacios y con el espíritu de sus costumbres y saberes, es el patrimonio de una ciudad. La cotidianidad, ese presente que se construye con el fluir de acciones y eventos, encuentra apoyo en la memoria acumulada en lugares documentos y en el incons ciente colectivo. La ciudad es, así, una construcción de la memoria que graba mensajes y signos ordenadores de la vida: la hora de levantarse, los lugares a recorrer, los lugares de trabajo, las horas laborales, las horas del amor... y cuya importancia se hace cada vez mayúscula, pues nadie puede avanzar a partir del olvido de sus es pacios de convivencia y comunicación ${ }^{19}$.

Entonces, el resultado de vivir en la ciudad es doble. Por un lado, material, porque los cuerpos son un efecto disciplinado por ella y, aunque mal administradas, minadas por el crimen y espantosas, tiene la capacidad de hacer de los ciudadanos seres más complejos. Pero, por otro lado, el efecto es psíquico,

Mary Giraldo con similares características en cuanto a la descripción de sitios-tabú de Bogotá. Cfr. Giraldo, L. M. (Selección y prólogo) "Cuentos Caníbales: Antología de nuevos narradores Colombianos". Bogotá: Alfaguara, 2002.

${ }^{17}$ Un estudio muy completo de la temática de la exdusión lo hallamos en manos del profesor Luís Villoro Toranzo, Premio de la UNAM en Investigaciones en Humanidades (México, 1989) y su artículo "Teoría de la injusticia: la exclusión" En: Rujana Quintero, M. Problemas actuales de la filosofía. Universidad Libre. Facultad de Filosofía. Cátedra Gerardo Molina Bogotá. Septiembre de 2000 pág. 17-65.

${ }^{18}$ Calvino, I. Op. Cit., p. 28.

${ }^{19}$ No en vano, desde hace un buen tiempo se puede conseguir con facilidad una gacetilla que recorre iconográficamente Bogotá desde el siglo XIX. El folletín se intitula "Historia Fotográfica de Bogotá"- con un total de 50 fotografías, de las cuales afecta ver el retroceso arquitectónico y estético de La Plaza de Bolívar actual si se compara con la de los años cuarenta del siglo pasado ávida de fuentes luminosas. Para un estudio más completo de este espacio urbano, Cfr. Pérgolis, J. C. "La plaza de Bolívar de Bogotá" En: Torres Tovar, C (Et Al) La ciudad: Hábitat de diversidad y complejidad. Universidad Nacional de Colombia, 2000 pág. 167-182. 
porque lo s constituye y les da una identidad, la cual se cristaliza a tra vés de la evocación constante de los lugares, las acciones y su evolución, a la manera de un 'álbum familiar es pacial'. Tal como dice Richard Sennett: "(...) una ciudad es un lugar donde la gente puede aprender a vivir con desconocidos, a compartir experiencias y centros de interés no familiares. La unifomidad embrutece, mientras que la diversidad estimula el espíritu. Además la ciudad ofrece a sus habitantes la posibilidad de desarrollar una conciencia de sí mismos más compleja y más rica (...) las personas pueden en ella desarrollar múltiples imágenes de sus identidades, sabiendo que lo que son varían en función de las personas que frecuentan. Es el poder de la diversidad: liberar de toda identificación arbitraria"20.

\section{Ciudad Como Promesa}

La ciudad también es una promesa, la ciudad se completa con lo ausente, con lo prometido. Realidad inacabada, a medio teminar, tal como lo representan las películas de Victor Gaviria Rodrigo D: no futuro (1986) o La vendedora de Rosas (1998) en el contexto antioqueño, o Sergio Cabrera con su cinta "La Estrategia del Caracol" (1993) y más recientemente la película de Rodrigo Triana "Como el Gato y el Ratón" (2002) para poner ejemplos representativos del ambiente bogotano. Todas las películas muestran casas a medio terminar, calles a medio asfaltar, personas a medio vestir y comer... y representan, como factor común, la presentación del colombiano como aquel sujeto anudado a una lógica perversa (quien instaura una ley particular a partir del conocimiento de La Ley) y que el profesor Pío Sanmiguel análoga a una lógica mestiza apoyándose en Dueñas, quien afima del mestizo: "(...) es el avivato, el que no tiene leyes, el que no tiene cómo participar pero participa, el que no puede casarse pero que produce mestizos todos los días, el que no puede blanquearse porque está prohibido, pero que se blanquea constantemente, que estás al margen de la ley, pero que le saca ventajas a la ley, que trampea, que contrabandea..." 21 . Con esto subrayamos, al tiempo, la promesa de un ciudadano en un espacio urbano que vive de promesa en promesa. La promesa, en suma, del cumplimiento de La Ley y no la instauración de la ley particular, tan característico de nuestra personalidad colectiva. Comportamiento éste mezclado y comandado por el imperativo de la producción de un goce, dentro de un lazo social que inmediatamente se transforma y nos deja 'fuera de juego', de juego lingüístico. Lógica caracterizada por el estado de cosificación en el que el sujeto toma la palabra ante el Otro y, deja como efecto una desaparición, un menos uno (-1). Todo indica que tal camino es inevitable, y tampoco lo evita el mestizo, porque siempre se produce al margen de la ley y la posterior edificación de una ley particular; se produce, pues,

${ }^{20}$ Sennett, R. “La nueva sociedad urbana” En: Le monde Diplomatique / el Dipló / Abril 2002. pág. 12.

${ }^{21}$ Dueñas, G. "Familia, mestizaje y formación de Estado" Post-data, 3 (1998), p. 17 Tomado de Sanmiguel, P. E. "Lógica mestiza” En: Sanmiguel, P. \& Figueroa, M. (comp.) ¿Mestizo yo? CES Y Universidad Nacional de Colombia, 2000, pág. 57 y ss. 
un excedente insólito, no absorbible por las tramas del canje, ese que desaparece tan pronto llega.

No sólo en estos últimos años, sino a lo largo de toda la historia, la tarea de formulación de ideas, valores sociales (del cual el del mestizo - y lo que ello significa- nos parece el más relevante) y símbolos está ligada a una tarea violenta, traumática y duradera, muchas veces invisible e irrepresentable, a saber: la producción del equipamiento sensorial e ideológico del ciudadano, la producción de los cuerpos y los sistemas de creencias que los hacen circular e interactuar (así sea para luego borrar al otro); en fin, la fabricación histórica de seres humanos funcionales con relación a una cierta lógica de interacción.

Y, como de golpe, se une la ciudad como caja o jaula con la ciudad como plan o promesa, y creemos ver esto en las arquitecturas hostiles de los barrios periféricos de la ciudad, a la vez que las promesas de mejoramiento de las mallas viales, como la ofrenda deslucida del Transmilenio, antes Troncal Caracas. La memoria colectiva deja recordar una calle muy rústica, tal como lo consiga el profesor Argüello: "Santa Fé de Bogotá, 1992. Troncal de la Caracas. Troncal en tres acepciones. De tronco, parte de la planta. Tronco como parte central de un ser vivo. Y truncar, obstruir, mutilar. Primero los árboles mutilados y la promesa de replanteamiento. Las promesas del replanteo son tan viejas como las mismas plantas. Viene después el encierro. Corrales construidos con tubos de metal. Una vía que dibuja el dorso espinal de la ciudad. Púas, chuzos, hasta cierta parte del trayecto. Después, muy curioso, flores en el pequeño trecho que falta. Control aversivo, perversivo y agresivo / Se ve de inmediato, la gran cicatriz, la gran huella de lo que se proyecta y que se nos proyecta. / Arteria o tronco primordial, no importa. De todas maneras es la vía que atraviesa nuestro cuerpo urbano. Es la vía que, como arteria, ha nacido enferma, esclerótica en su circulación. Mutilada y neurótica, en su proyección simbólica..."22

Es evidente notar que hoy se sigue domesticando el cuerpo de forma casi militar, ahora en un escenario diferente que imita las estaciones de un metro, pero que no lo sustituye funcionalmente. Asombra cómo el us uario de Transmilenio hace parte de una interminable fila india sin oponerse, sometido a trasladarse por corredores como en lotes de ganado, obedeciendo ciegamente un régimen aplastante gobemado por fastidiosos jóvenes que hacen las veces de policías, para luego meter el cuerpo a los otros cuerpos y apretujarlo en la espesura de una colectividad de "48 pasajeros sentados y 163 en total", que evidentemente sobrepasa tal cantidad en "horas pico", quedando así el cuerpo torturado y dizque en beneficio de una "cultura ciudadana" que gruñe en una ciudad estática y aún pre-moderna que ya duerme como organismo antes de la media noche y que se caracteriza por presentar abiertamente la carencia de una ética ciudadana, es decir, la escasez de conciencia con respecto a la esfera de lo público, puesta en escena como aprehensión malsana del concepto de Solidaridad.

\footnotetext{
${ }^{22}$ Argüello, R. "Ciudad gótica: Circulación y tránsito truncado" En: Ensayos de simbólica y diabólica urbana Asociación Colombiana de Semiótica, 1998 pág. 14 (las negritas nos pertenecen). 


\section{CIUDADCOMO escenario(s) productor(Es) de imaginarios sociales}

Lo imaginario, siempre necesita de lo simbólico, de los códigos para su materialización. Es decir, lo imaginario siempre necesita simbolizarse. Es justamente Armando Silva, quien trae a colación este tipo de relación imaginariosimbólico, para argumentar sobre los imaginarios urbanos. Y es que para comprender la relación imaginario-real, en la historia de la humanidad las imaginaciones fundamentales son el origen de los preceptos sociales. Así, lo imaginario afecta los modos de simbolizar aquello que conocemos como realidad. En rigor, el imaginario implica la capacidad de hacer surgir como imagen algo que no es, ni fue. "(...) Lo imaginario afecta, filtra y modela nuestra percepción de la vida y tiene gran impacto en la elaboración de los relatos de la cotidianidad. La ciudad viene a ser un espacio privilegiado de la cotidianidad, pronunciada por los ciudadanos diariamente, y tales pronunciamientos, la fabulación, el secreto o la mentira, constituyen, tres estrategias en la narración del ser urbano. Los relatos urbanos focalizan la ciudad, generando distintos puntos de vista" ${ }^{23}$ Casos memorables dan cuenta de ello. Así, por ejemplo, aquel que afima que el cerro de Monserrate es un volcán domido, o que en la Universidad Nacional existen laberintos subterráneos donde los estudiantes se reúnen a consumir sustancias psicotrópicas; que Melgar es un sitio exclusivo de comercio sexual; también numerosos "chismes criminales" como los suscitados por el cartel de Medellín, "Los extraditables", etc.

Bogotá, entonces, incluida en una arquitectura de sentidos, de sentidos neobarrocos, vale decir. Término éste tomado nuevamente de Omar Calabrese y que remite a la forma de percepción de las producciones culturales actuales, donde la repetición, el exceso de detalles, la fragmentación, la inestabilidad, la metamorfosis, la complejidad, el laberinto y otras características anexas, definen las zonas metropolitanas bogotanas como espacios escriturarios, donde se inscribe, se corta, se pega y se disuelve nuestra historia como dinamismo perverso y sin coincidencias.

Para finalizar una pregunta para dejar abierta la reflexión: nuestra ciudad, ¿es una de esas que no tiene dolientes, que no tiene quién la llore?

El urbanita tiene la vida en sus manos -así todo lo indica aparentemente-, la posibilidad de optar por su destino; pero entonces no sabe mucho que hacer con él. Entonces, comienza a luchar por sus vacíos pasando de tratamiento en tratamiento (psicoterapias, psicoanálisis, medicinas alternativas...), o concentrándose en el éxtasis, el yajé, el yopo ${ }^{24} \mathrm{u}$ otras experiencias sensoriales producidas con permiso de la autoridad competente (antidepresivos, estimulantes o tranquilizantes). Este es urbanita: sujeto deprimido, ansioso, colérico, temeroso y

${ }^{23}$ Silva, A. Op, cit, pág. 94-95

24 Yajé: sustancia que produce efectos alucinógenos. Yopo: sustancia estimulante. Estas substancias son utilizadas por comunidades indígenas (v.gr. Muinane, Uitoto, Sicuani, etc) y apetecidas por Is "comunidades blancas". 
violento que vive más en la hiper-realidad de los set televisivos de Expedición Robinson, Popstars, Protagonistas de Novela o Laura en América que en el mundo real, identificado con unos sujetos cotidianos, pero inflados artificialmente por los mass media (Jaider, Rolando, Isa...), y que no son más que soquetes que re-producen nuestra condición y que ayudan a mantener un montaje irreal de los espacios públicos y sus interacciones.

Eso somos nosotros, seres invadidos de mensajes y objetos desechables ofrecidos en los centros comerciales, los escenarios deportivos, las universidades, las licoreras, los videoclips y cuanto espacio imaginario de pertenencia y exclusión se instaura, con lo cual quedamos reducidos a unos intereses insospechados e inconscientes, como títeres de las formas de sociabilidad urbana que ellos expresan. No importa la edad, importa ser "juvenil", ¿cierto?. Así las cosas, los dolientes somos a la vez las víctimas ( ¿?) y nuestros cuerpos se reducen a la imagen promovida por la ciudad m isma; ciudad neobarroca, ciudad-cárcel, ciudadfuneraria, ciudad-masmediática, ciudad-gótica; enome Centro Comercial.

\section{BIBLIOGRAFÍA}

Anderson, B. "Comunidades imaginadas. Reflexiones sobre el origen y la difusión del nacionalismo", México: Fondo de Cultura Económica, 1991.

Argüello, R. "Ciudad gótica: Circulación y tránsito truncado" En: Ensayos de simbólica y diabólica urbana Asociación Colombiana de Semiótica, 1998.

Calabrese, O. "La era neobarroca" Madrid: Cátedra, 1989.

Calvino, I. "Las ciudades invisibles", Madrid: Biblioteca El Mundo. 1999.

Chaparro Madiedo, R . “Opio en las nubes” Bogotá: Proyecto Editorial, 1998.

Dueñas, G. "Familia, mestizaje y formación de Estado" Post-data, 3 (1998), p. 17

Freud, S "Lo ominoso" (1919) En: O. C. Buenos aires: Amorrortu, 1991, Tomo XVII

Giraldo, L. M. (Selección y prólogo) "Cuentos Caníbales: Antología de nuevos narradores Colombianos". Bogotá: Alfaguara, 2002.

Hare, R. "Wofur sind Stadte da? Die Ethic der Standtplanung" En: Meggle, G. Zum moralistchen Denken, Bd, 2, Frankfurt, 1995.

JARAMILLO VÉLEZ, R. "Colombia: la modemidad postergada". Argumentos, 1999.

Pardo, J. L. "Las formas de la exterioridad”, Valencia: Pre-textos, 1992.

Pérgolis, J. C. "La plaza de Bolívar de Bogotá" En: Torres Tovar, C (Et Al) La ciudad: Hábitat de diversidad y complejidad. Universidad Nacional de Colombia, 2000.

"Bogotá fragmentada" Bogotá: Tercer mundo, editores, 1998.

"La ciudad de los milagros y las fiestas" Bogotá: Tercer Mundo,

1998.

Rama, A. "Ciudad letrada” Hanover: Ediciones del Norte, 1984. 
Segura, C \& Cabarcas, H. "La dignidad del coraje. Textos de Ramón de Zubiría". Colección el "Álamo y el Ciprés 2" Bogotá: Instituto Caro y Cuervo y Universidad de los Andes, 1998.

Sennett, R. "El declive del hombre público" Barcelona: Península, 1978.

Abril 2002.

Silva, A. "Imaginarios urbanos: cultura y comunicación urbana" Bogotá: Tercer Mundo, editores. Tercera edición, 1997.

Simmel, G. "El individuo y la libertad. Ensayos de crítica de la cultura" Barcelona: Península, 1986.

Torres Tovar, C (Et Al) "La ciudad: Hábitat de diversidad y complejidad " Universidad Nacional de Colombia, 2000.

Villoro Toranzo, L. "Teoría de la injusticia: la exclusión" En: Rujana Quintero, M. (comp.) Problemas actuales de la filosofía. Universidad Libre. Facultad de Filosofía. Cátedra Gerardo Molina Bogotá. Septiembre de 2000.

Viviescas, F. \& Giraldo, F. "Colombia: el despertar de la modemidad" Bogotá: Foro Nacional por Colombia, 1991.

Xibilé Muntaner, J. "La situación posmodema el arte urbano" Medellín: Fondo editorial Universidad, 1993.

(Comp.) "La escritura del cuerpo, el cuerpo de la escritura" Medellín: Universidad Nacional de Colombia, 2000.

Zarone, G. "Metafísica de la ciudad. Encanto utópico y desencanto metropolitano" Valencia: Pre-textos, 1993. 